\title{
Tartışma: "Bitlis Hava Kirliliği Emisyon Envanteri ve Sağlık Etkilerinin Çoklu Lineer Regresyonla Tahmini” Başlıklı Yayınla İlgili Yorum (Doğal Afetler ve Çevre Dergisi, Ocak 2019, 5(1): 1-10)
}

\author{
Edip Avşar, ${ }^{*}$ \\ ${ }^{1}$ Bitlis Eren Üniversitesi, Mühendislik Mimarlık Fakültesi, Çevre Mühendisliği Bölümü, 13000 Bitlis.
}

\section{Özet}

Doğal Afetler ve Çevre Dergisi'nde yayınlanan "Bitlis Hava Kirliliği Emisyon Envanteri ve Sağllk Etkilerinin Coklu Lineer Regresyonla Tahmini" isimli yayında (Ocak 2019, 5(1): 1-10) Bitlis'te 2015 yılında yakılan yakıt miktarından hareketle; $S_{x}, N_{x}$, PMıv ve CO parametreleri için kütlesel debiler hesaplanmıştır. Ayrıca Bitlis'te 2012-2015 yılları arasında mevcut hastanelere solunum yoluyla ilgili başvuran hasta sayıları elde edilmiştir. Hasta sayıları ve emisyon verileri kullanılarak 2015 yılı hasta sayıları tahmin edilmiş ve hesaplanan hasta sayısı ile elde edilen hasta sayısı arasında yüksek korelasyon görüldüğü belirtilmiştir. Çalışmada çok önemli hatalar mevcuttur. Hesaplamaya esas alınan kömür miktarl ve hesaplanan emisyon faktörlerinin bazıları hatalı olup bu nedenle elde edilen emisyon envanteri tamamen yanlıştır. Bu durumda elde edilen korelasyon değeri de tamamen rastlantısaldır. Bu makaleden faydalanacak okuyucuların bu hataları görmesi açısından yapılan tespitler değerlendirme olarak çalışmada verilmiştir

\section{Discussion: Comments on the Article Titled as "Bitlis Air Pollution Emission Inventory and Estimation of Health Effects by Multiple Linear Regression" (Journal of Natural Hazards and Environment, January 2019, 5(1): 1-10)}

\begin{abstract}
According to the article published in Journal of Natural Hazards and Environment, titled as "Bitlis Air Pollution Emission Inventory and Estimation of Health Effects by Multiple Linear Regression" (January 2019, 5(1): 1-10); mass discharges for the parameters of $S O_{x}, N O_{x}, P M_{10}$ and $\mathrm{CO}$ were estimated by means of 2015 burned coal data in Bitlis. In addition, the number of patients admitted to hospitals for respiratory diseases in Bitlis between 2012 and 2015 were obtained. The patient numbers and the emission data were used to estimate the number of patients in 2015 and a high correlation was observed between the number of patients calculated and the number of patients obtained. There were very important errors in the study. The amount of coal taken into account and some of the calculated emission factors were inaccurate, thus, the emission inventory was completely wrong. In this case, the correlation value was completely random. In this discussion, the findings of the discussed article were evaluated so that the readers benefiting from discussed article can see these mistakes.
\end{abstract}

$\underline{\text { Keywords }}$

Air Pollution, Calculation of Emission Inventory, Healthy Effects of Pollutants, Multiple Linear Regression Analysis

\section{Değerlendirme}

Çalışmada Bitlis’te 2015 yılında yakılan yakıt miktarından hareketle; $\mathrm{SO}_{x}, \mathrm{NO}_{\mathrm{x}}, \mathrm{PM}_{10}$ ve $\mathrm{CO}$ parametreleri için kütlesel debilerin hesaplandığı ve bu veriler ile hastanelere solunum yoluyla başvuran hasta sayılarının çoklu lineer regresyona (ÇLR) tabi tutulması ile hasta sayısının tahmin edildiği belirtilmiştir. Çalışmada çok önemli hatalar mevcuttur. Şöyle ki;

Çalışmanın özet kısmında, çalışmada $\mathrm{SO}_{\mathrm{x}} \mathrm{NO}_{\mathrm{x}} \mathrm{CO}$ ve $\mathrm{PM}_{10}$ ölçüm değerlerinden yararlanıldığı belirtilmekle birlikte çalışmada ölçüme yönelik herhangi bir veri verilmemiştir. Çalışma kapsamında herhangi bir ölçüm yapılmamıştır.

Çalışmada 2015 yılında Bitlis İli’nde yakılan kömür miktarı $55118 \mathrm{~kg}$ olarak verilmektedir. Ancak yayında da kaynak gösterilen Bitlis İli 2015 Yılı Çevre Durum Raporu'na (ÇDR) göre Bitlis’te ısınma amaçlı olarak;

- 55117 ton ithal kömür,

- 15000 ton TKI'den alınan sosyal yardımlaşma kömürü ve

- $800 \mathrm{~m}^{3}$ fuel oil yakıldığı anlaşılmaktadır. 
Bahsi geçen kaynaktaki yakıt verileri Tablo 1 ve Tablo 2'de aynı şekliyle verilmiştir (ÇŞM 2016).

Tablo 1: ÇDR'ye göre Bitlis'te 2015 yılında tüketilen kömür miktarları (Orijinal kaynakta verildiği şekliyle verilmiştir)

\section{Çizelge A.3 - Bitlis İlinde 2015 Yılında Evsel Isınmada Kullanılan Katı Yakıtların Cinsi, Yakıtların Özellikleri ve Bu Yakıtların Temin Edildiği Yerler (Bitlis Çevre ve Șehircilik İl Müdürlüğü, 2016)}

\begin{tabular}{|c|c|c|c|c|c|c|c|}
\hline $\begin{array}{c}\text { Yakıtın } \\
\text { Cinsi }\left(^{*}\right)\end{array}$ & $\begin{array}{c}\text { Temin Edildiği } \\
\text { Yer }\end{array}$ & $\begin{array}{c}\text { Tüketim } \\
\text { Miktarı } \\
\text { (ton) }\end{array}$ & $\begin{array}{c}\text { Alt Isıl } \\
\text { Değeri } \\
(\mathrm{kcal} / \mathrm{kg})\end{array}$ & $\begin{array}{c}\text { Uçucu } \\
\text { Madde } \\
(\%)\end{array}$ & $\begin{array}{c}\text { Toplam } \\
\text { Kükürt } \\
(\%)\end{array}$ & $\begin{array}{c}\text { Toplam } \\
\text { Nem } \\
(\%)\end{array}$ & $\begin{array}{c}\text { Kül } \\
(\%)\end{array}$ \\
\hline Ithal Kömür & $\begin{array}{c}\text { Kömür Satış } \\
\text { Bayileri }\end{array}$ & 55.117 & En az 6200 & $12-33$ & En çok 1 & En çok 11 & En çok 18 \\
\hline $\begin{array}{c}\text { Yerli Kömür } \\
\text { Sosyal } \\
\text { Yardımlaşma } \\
\text { Vakfı Kömürü }\end{array}$ & TKi & 15.000 & En az 4000 & & En çok 2,3 & En çok 30 & En çok 30 \\
\hline
\end{tabular}

$\left(^{*}\right)$ Yerli kömür, ithal kömür, briket, biyokütle, Sosyal Yardımlaşma Vakfı kömürü, odun gibi.

Tablo 2: ÇDR'ye göre Bitlis Illinde 2015 yılında ısınma amaçlı tüketilen fuel-oil miktarları (Orijinal kaynakta verildiği şekliyle verilmiştir)

Çizelge A.7 - Bitlis İlinde 2015 Yılında Kullanılan Fuel-oil Miktarı (Bitlis Çevre ve Şehircilik İl Müdürlüğü, 2016)

\begin{tabular}{|c|r|r|r|}
\hline Yakıtın Kullanıldığı Yer & Tüketim Miktarı $\left(\mathbf{m}^{\mathbf{3}}\right)$ & Isıl Değeri (kcal/kg) & Toplam Kükürt (\%) \\
\hline Konut & 800 & - & - \\
\hline Sanayi & - & & - \\
\hline
\end{tabular}

Ayrıca yukarıda Tablo 2'deki değerin de sadece kamu tarafından yapılan ihaleleri gösterdiği konutlardaki kullanımı içermediği düşünülmektedir. Elektronik Kamu Alımları Platformu (EKAP) üzerinden Bitlis’te yapılan ihalelere bakıldığında, sadece Bitlis Eren Üniversitesi'nin 2015 yılına hazırlık için 2014 Ekim ayında $650 \mathrm{~m}^{3} 4$ nolu fuel oil satın aldığ 1 görülebilir (EKAP 2018).

Sonuç olarak Bitlis’te 2015 yılında toplamda 70117 ton kömür ve $800 \mathrm{~m}^{3}$ fuel oil yakıldığ İl Çevre ve Şehircilik Müdürlüğü tarafından beyan edilmiş olup makalede hesaplamalara esas alınan $55118 \mathrm{~kg}$ kömür değeri yakılan kömür değerinden 1272 kat küçüktür. Ayrıca fuel oil tüketiminin de hesaba katılmaması emisyon envanteri hesabındaki hatayı daha da arttırmaktadır. Buna göre çalışmada yapılan tüm emisyon envanteri hesabı hatalı olup bilimsel bir değeri yoktur (ÇŞM 2016).

Yayında, emisyon envanterinin çıkartılmasında Avrupa Çevre Ajansı (EEA) tarafından verilen Hava Kirletici Emisyon Envanteri Kılavuz Kitabı'ndan (HKEEKK) (air pollutant emission inventory guidebook) faydalanıldığı ancak bu kaynağa referans verilmediği görülmektedir (EEA 2016).

Yayında, $\mathrm{SO}_{2}$ için EEA (2016)'da verilen emisyon faktörlerinde; kükürt içeriğinin $(\% \mathrm{~S}) \% 1,2$ ve alt 1sıl değerin ise (AID) $5731 \mathrm{kcal} / \mathrm{kg}$ olarak varsayıldığı ancak Bitlis’te kullanılan kömürün çeşit ve özelliklerinin bu duruma uygun olmadığı belirtilmiştir. Bu nedenle $\mathrm{SO}_{2}$ emisyon faktörü hesabında Isınmadan Kaynaklanan Hava Kirliliğinin Kontrolü

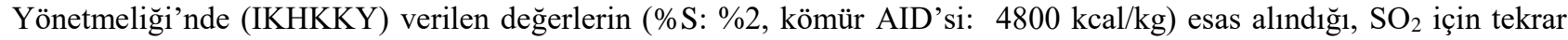
emisyon faktörü hesaplandığı ve yayında mevcut Tablo 1'de hesaplanan emisyon faktörlerinin verildiği belirtilmiştir.

Halbuki ÇDR'de külde tutulan kükürt içeriği hariç Bitlis'te kullanılan kömürlerin alt ısıl değeri ve \%S içeriği verilmiştir. ÇDR'ye göre Bitlis'te yakılan kömürün büyük kısmı ithal kömürdür. Yayında, $\mathrm{SO}_{2}$ emisyon faktörü hesabında esas alınan kömür spesifikasyonu ise "IKHKKY Tablo 11'de Sınır Değerlerinin Aşıldığı İl ve İlçelerde Kullanılacak Yerli Kömürlerin Özellikleri” olup Bitlis’te kullanılan kömür spesifikasyonu ile uyuşmamaktadır.

Burada bir yaklaşım olarak Bitlis’te kullanılan iki farklı kömürün ısıl değer, \%S içerikleri ve kömürlerin kullanım miktarlarından hareketle ağırlıklı ortalamalar alınarak tek bir \%S ve AID hesaplanabilir. Yapılan hesaplamalar eşitlik 1 ve eşitlik 2'de verilmiştir.

$$
\begin{aligned}
& \% S=\frac{((55117 \text { ton } \times 1)+(15000 \text { ton } \times 2,3))}{(55117+15000) \operatorname{ton}}=1,28 \\
& A I D=\frac{((55117 \text { ton } \times 6200 \mathrm{kcal} / \mathrm{kg})+(15000 \text { ton } \times 4000 \mathrm{kcal} / \mathrm{kg}))}{(55117+15000) \operatorname{ton}}=5729 \mathrm{kcal} / \mathrm{kg}
\end{aligned}
$$


Elde edilen değerlerin, yazar tarafından HKEEKK'da verildiği ve kullanılan kömürle uygun olmadığı belirtilen \%S ve AID verileri (\%S: 1,2; AID: $5731 \mathrm{kcal} / \mathrm{kg}$ ) ile uyuştuğu, $\mathrm{SO}_{2}$ için HKEEKK'da verilen emisyon faktörlerinin rahatlıkla kullanılabileceği görülmektedir. Bu durumda, $\mathrm{SO}_{2}$ için emisyon faktörü hesaplamaya gerek olmadığı ve hesapla bulunan emisyon faktörlerinin de bu durumda gerçek durumu yansıtmadığı açıktır.

Yayında $\mathrm{SO}_{2}$ emisyon faktörü hesabı için tek bir kalorifik değer ve \% $\mathrm{S}$ içeriği alınmasına rağmen 2 farklı emisyon faktörü hesaplandığı görülmektedir. Bu durumda, ikinci emisyon faktörünün nasıl hesaplandığına dair yayında bir açıklama yoktur. Ancak yazarın bu içeriği aynen aldığı ve kaynak göstermediği Turp ve Turp (2015) yayınında, ikinci hesaplama için alt ısıl değerin $6400 \mathrm{kcal} / \mathrm{kg}$ ve \%S içeriğinin \%1 olarak alındığı görülmekte olup, yayında mevcut Tablo 1'deki $\mathrm{SO}_{2}$ emisyon faktörünün hesaplanmasında kullanılan diğer \%S ve AID verisinin buradan geldiği anlaşılmaktadır.

Zaten yayında, $\mathrm{SO}_{2}$ emisyon hesabı ile ilgili olarak $\mathrm{EF}_{\mathrm{S} 02, \mathrm{k}}$ formülasyonu üzerinde verilen son paragrafın ve Tablo 1'in Turp ve Turp (2015)'de mevcut sayfa 76'daki ikinci paragraf ve Tablo 2.2'den aynen alındığı ancak referans verilmediği görülebilir.

İthal kömürün sobada yakılması sonucu ortaya çıkan emisyonlar için yayında mevcut Tablo 1'de verilen emisyon faktörleri incelendiğinde;

- $\quad \mathrm{SO}_{2}$ için $1717,98 \mathrm{~kg} / \mathrm{ton}$

- $\mathrm{PM}_{10}$ için $1212,04 \mathrm{~kg} / \mathrm{ton}$

- $\quad$ CO için $13133,76 \mathrm{~kg} /$ ton

gibi gerçeğe aykırı değerlerin verildiği görülmektedir. Bu açıdan bakıldığında 1 ton kömür yanmasından;

- $\quad 1,7$ ton $\mathrm{SO}_{2}$;

- 1,2 ton $\mathrm{PM}_{10}$ ve

- $\quad 13,1$ ton $\mathrm{CO}$

çıkacağı görülmekte olup, bu durum imkansızdır. Bu emisyon faktörleri haricindeki diğer emisyon faktörleri de HKEEKK'dan alınmış olsa bile, bu referans kaynakta tek bir tablo ve tek bir yakıcı çeşidi olmadığı için bu değerlerin kaynaktaki hangi tablolardan alındığının belirtilmesi yapılan hesapların izlenilebilir olması için olmazsa olmazdır.

Çalışmanın materyal kısmında kömür kullanıldığı belirtilmesine rağmen doğal gaz yakımı için <50 kW'lik kombi kullanıldığı gibi anlamsız bir ibareye yer verilmiştir. Makalede doğal gazla ilgili bir hesap yapılmadığ1 gibi 2015 yılında Bitlis'te doğalgaz da mevcut değildir, Bitlis’te doğal gaz kullanılmadığg ÇDR'de de belirtilmektedir (ÇŞM 2016).

Yayında tüketilen kömür verilerinin verildiği Tablo 2 incelendiğinde; değerlerin sayısal olarak hatalı olmasının yanında, Temmuz ayında yakılan kömür miktarının Şubat ayında yakılan kömür miktarından daha fazla olması gibi mantık hataları da içerdiği görülmektedir. Dolayısıyla sayısal olarak hatalı olması dışında, bu verilen yakılan kömür değil, satılan kömür olduğu düşünülmektedir. Zaten yayında verilen meteorolojik verilerden hareketle, en düşük sıcaklıkların görüldüğ̈̈ mevsimler ocak, şubat ve aralık aylarıdır. En fazla kömür satılan aylar ise mayıs ekim ve kasım aylarıdır. Bu durumda bu verilerin kömür yakılmasıyla ilişkili olmadığını göstermektedir. Isınma kaynaklı hava kirliliği ile ilgili envanter çalışmalarında genel olarak Mayıs Eylül arası dönemde yakıt yakılmadığı kabul edilmektedir (Kaynakoğlu 2010; Odabaş 2009).

Dolayısıyla Tablo 2'deki değerlerin mertebe olarak hatalı olması, yakılan değil satılan kömür üzerinden verilmesi hususları göz önüne alındığında, yayında elde edilen korelasyon değerinin rastlantısal olduğu ve bilimsel bir değeri olmadığı açıktır. İstatistiki veriler arasında bir korelasyon görülmesi bu verilerin arasındaki ilişkinin her zaman mantıklı olduğu anlamına gelmemektedir. Bu durumda buna bir örnektir.

Çalışmada çoklu lineer regresyon (ÇLR) ile yapılan tahminde 2012-2013-2014 yıllarında hastanelere başvuran hasta değerlerinin nerede ve nasıl kullanıldığı belli değildir. Bunlara metodoloji kısmında atıf yapılmamıştır. ÇLR metodu ile elde edilen ve hasta sayısını veren denklem belirsizdir. Halbuki yayında bu denklemin ulaşılabilir ve doğruluğunun kontrol edilebilir olması gerekir.

Giriş bölümünde $\mathrm{SO}_{2}, \mathrm{NO}_{\mathrm{x}}, \mathrm{PM}_{10}$ ve $\mathrm{CO}$ ile ilgili tanımlamalar blok halinde 2016 Bitlis İl Çevre Durum Raporu'ndan alınmıştır. Kaynak gösterilmekle birlikte yayının \%8'e tekabül eden bir kısmı tek bir kaynaktan kopyalanmıştır (ÇŞM 2017).

Sonuç olarak, emisyon verileri ile hasta sayıları kullanılarak ÇLR ile geleceğe yönelik hasta sayılılarının tahmin edildiği ve yüksek korelasyon elde edildiği belirtilen çalışmada, yakılan yakıt verileri ve hesaplanan emisyon envanteri hatalıdır. Bu durumda bu veriler kullanılarak elde edilen korelasyon verisi hatalı ve rastlantısaldır.

\section{Kaynaklar}

ÇŞM, (2016), Bitlis İli 2015 Yllı Çevre Durum Raporu, Bitlis İl Çevre ve Şehircilik Müdürlügü, http://webdosya.csb.gov.tr/db/ced/ editordosya/Bitlis2015.pdf, [Erişim 18 Ekim 2018].

ÇŞM, (2017), Bitlis İli 2016 Yllı Çevre Durum Raporu, Bitlis İl Çevre ve Şehircilik Müdürlüğü, http://webdosya.csb.gov.tr/db/bitlis/ icerikler/2016-cevre-durum-raporu-20180226094608.pdf, [Erişim 18 Ekim 2018].

EEA, (2016), EMEP/EEA air pollutant emission inventory guidebook 2016, Europen Environment Agency, https://www.eea.europa.eu/ publications/emep-eea-guidebook-2016, [Erişim 18 Ekim 2018].

EKAP, (2018), Elektronik Kamu Alım Portalı, https://ekap.kik.gov.tr/EKAP/Ortak/IhaleArama/index.html, [Erişim 18 Ekim 2018]. 
Kaynakoğlu H., (2010), Isınma Kaynaklı Emisyon Envanterinin Hazırlanması, Büyükşehirlerde Hava Kalitesi Yönetiminin Geliştirilmesi Projesi, http://ikonair.cob.gov.tr/ikonair/Files/sunumlar_cal\%C4\%B1stay/3.\%20calistay/\%C4\%B1s\%C4\%B1nma \%20envanteri.pdf, [Erişim 18 Ekim 2018].

Odabaş B.B., (2009), Adapazarı İlçesinde Isınma Kaynaklı Emisyonların Analizi ve Envanterlenmesi, Yüksek Lisans Tezi, Sakarya Üniversitesi Fen Bilimleri Enstitüsü, http://www.sahakk.sakarya.edu.tr/documents/presentations/Heating_sourced_emissions_ inventory_TEZ.pdf, [Erişim 18 Ekim 2018].

Turp S.M., Turp G.A., (2015), City of Bitlis 2014 Air Pollution Emission Inventory, Bitlis Eren Univ. J. Sci \& Technol. 5(2), 75-80. 